\title{
Gold in the Southern African Iron Age
}

\author{
A TECHNOLOGICAL INVESTIGATION OF THE MAPUNGUBWE AND OTHER FINDS
}

\author{
Andrew Oddy \\ Conservation Division, The British Museum, London, United Kingdom
}

\begin{abstract}
The finds of worked gold artifacts at Mapungubwe and ot ber areas in the Southern A frican interior dating back to about the end of the first millennium A.D. are of great interest in revealing the level and techniques of manufacturing carried on in the region at this time.
\end{abstract}

\section{The Iron Age in Sub-Saharan Africa}

In Egypt, copper was known from at least the fourth millennium B.C. and iron from about 1000 B.C., although the latter did not become a commonly used metal for several more centuries. The history of metallurgy followed a similar course in the Sudan and Northern Ethiopia, but in the eastern part of Southern Africa the people passed directly from a Stone Age civilization of hunters and gatherers to that of farmers with a knowledge of iron and gold, bypassing the experience of an intervening Copper or Bronze Age. There is, however, some evidence that the Khoikhoin (or Hottentot) people of the western part of Southern Africa had some knowledge of copper working without any expertise in the working of iron.

The key to the knowledge of iron in sub-Saharan Africa is probably the Kingdom of Meroe, which flourished in the Sudan in the middle and later part of the first millennium B.C. Iron was the basis of the Meroitic economy, and from Meroe there are natural lines of communications to the Red Sea to the east, and Lake Chad to the south, as well as to the north along the Nile.

It is the spread of the knowledge of iron to the south which is most important, as, by at least the 3 rd century A.D., there had been a radical change in the way of life in Southern Africa, which is most

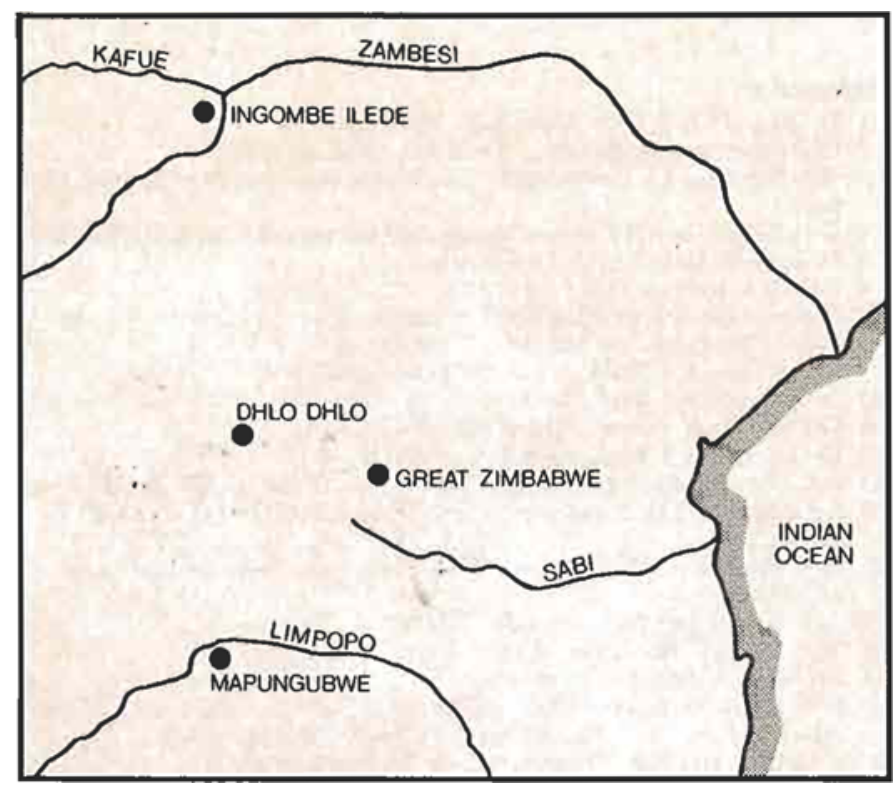

Fig. 1 Map of the main sites of the later African Iron Age where gold has been found. easily followed by the introduction of a new and characteristic type of pottery as far south as Natal. This pottery is associated with the working of iron and the herding of sheep, goats and cattle and its introduction is marked by the use of the term Early African Iron Age. (It is important not to confuse the African Iron Age with that in Europe and the Middle East which occurred much earlier). The spread of iron-using seems to be connected with the spread of Bantu languages, although much more work is necessary before the relationship between the two is fully understood.

From very approximately the end of the first millennium A.D. we begin to find evidence for the mining of copper and gold, the building of simple stone walls, and trade with the East Coast. Of course, one of the commodities which the Arabs on the East Coast wanted was gold, and it is no coincidence that the arrival of trade goods in the interior should correlate with the first Arab accounts of a trade in gold from this area.

From the 11th century onwards trade rapidly increased from the interior to the East Coast and the rcaring of cattle became more important. These cultural changes are termed the Later Iron Age by archaeologists, and it is to this period that the indigenous production of the gold jewellery and gold figurines, which are the subject of this article, belong.

\section{Mapungubwe, Great Zimbabwe and Ingombe Ilede}

Gold has been found at numerous sites of the Later Iron Age, but, with three exceptions (Figure 1), the quantities have been small.

The earliest of the finds are from Mapungubwe $(1,2)$, a hill about two kilometres south of the Limpopo and at which burials containing gold were discovered fifty years ago. It appears that the hilltop was a kind of acropolis, inhabited by the ruling class, while the ordinary people lived in the valley below. During the Later Iron Age phase substantial wattle and daub houses were built, and stone revetted terraces were also constructed. The burials which contained the gold were found on top of the hill and are now dated to between 1000 and 1150 A.D. They represent the most spectacular and rich graves thus far excavated from the Iron Age in Southern Africa.

If Mapungubwe has produced the best gold, Great Zimbabwe and other sites in that region have yielded the greatest Iron Age development of stone-building techniques, which probably occurred in the 14 th and 15 th centuries A.D. (3). Unfortunately most of the gold finds from the ruins at Great Zimbabwe are not stratified and were recovered by means of uncontrolled excavation before the Second World War; it is only relatively recently that 
careful excavations on the site have led to a better understanding of the chronology of the finds (4).

Also dated to the 14 th and 15 th centuries are the rich burials from Ingombe Ilede on the Zambesi River near its confluence with the Kafue $(5,6)$. These sites seem to have been inhabited by traders who were engaged in exporting gold to the East Coast, and are important not only for the finds of gold, but also for the fact that metalworking tools were also deposited in the graves.

\section{Gold at Mapungubwe}

The gold artifacts from the burials at Mapungubwe fall into three distinct classes: beads, wire bracelets and foil used to cover wooden carvings.

\section{Foil}

By far the most spectacular of the artifacts are the pieces of gold foil which were used to cover wooden carvings of animals, a sceptre and a bowl. Examination under the microscope shows that the inner surface of most of the pieces has a rough texture which suggests that it was hammered out on a stone anvil (Figure 2). The most famous of the sheet-gold pieces is a rhinoceros, the torso and legs of which appear to have been made originally from one sheet of gold, this having been shaped mainly by creasing, but also slightly by repoussé hammering. In particular, the hips of the front legs have been delineated nicely. The head and horn are both made from separate pieces of sheet, and the overall shape of the animal was achieved mainly by pressing the foil over a wooden carving and holding it in place with gold pins. The ears are made from slightly thicker foil and the tail has been hammered from a nugget and decorated by making incisions near the end with a sharp tool.

It is the presence of significant numbers of gold pins (Figure 3) among the finds from Mapungubwe which prove that the original carvings were of wood, rather than ivory, as the pins would be too soft for use with a hard substrate. Examination of the numerous loose pieces of gold foil which cannot at the moment be reconstructed into complete artifacts, shows, in detail, how these sculptures were made.

The goldsmiths at Mapungubwe seem to have had very little appreciation of the art of repoussé working of the gold foil once they had made it, and much of the threedimensional shaping was achieved by folding, creasing (Figure 4) and pleating of

Fig. 3 Small gold nails or pins which were used to attach the sheets of gold foil to wooden carvings at Mapungubwe

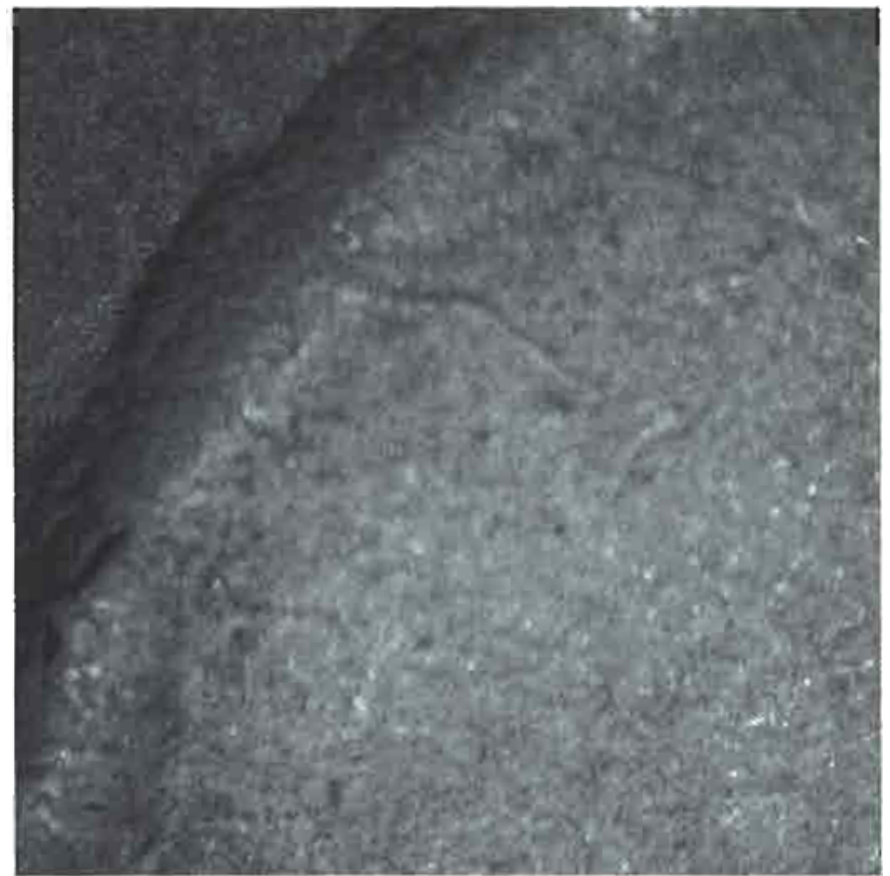

Fig. 2 The rough inner surface of a piece of gold foil from Mapungubwe which was once part of a model of an animal. The rough texture suggests that the gold was hammered out on a stone anvil

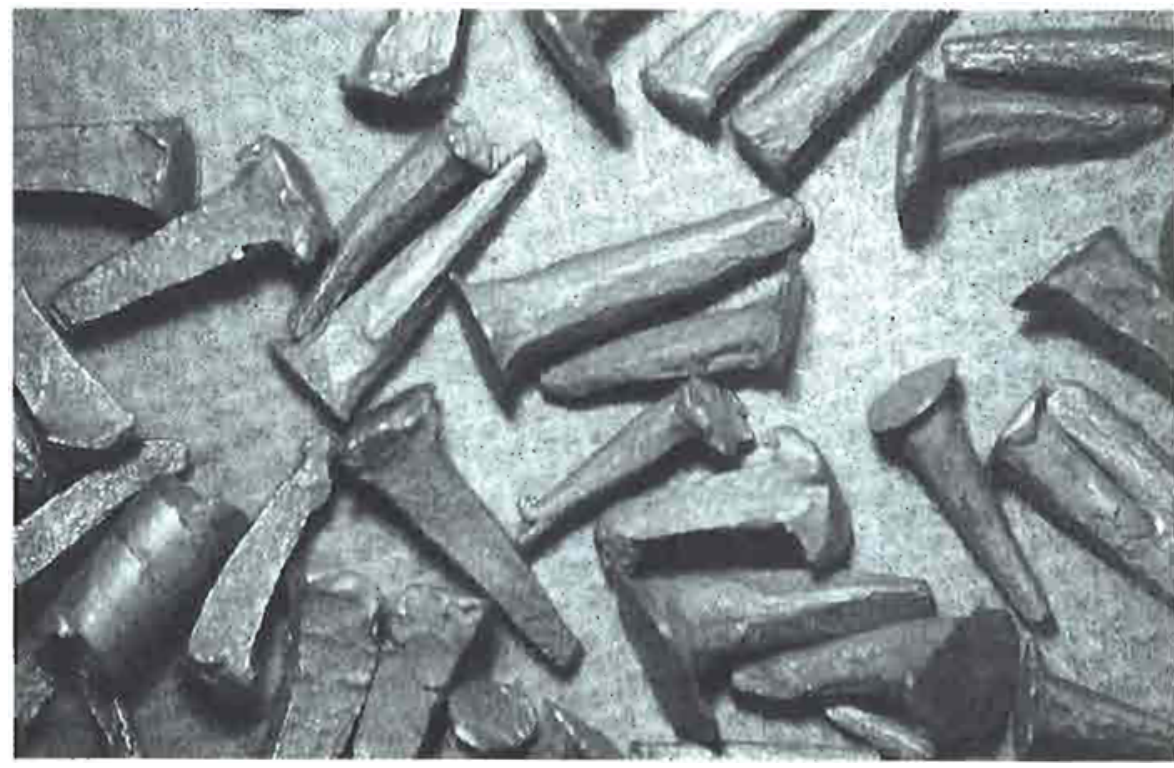




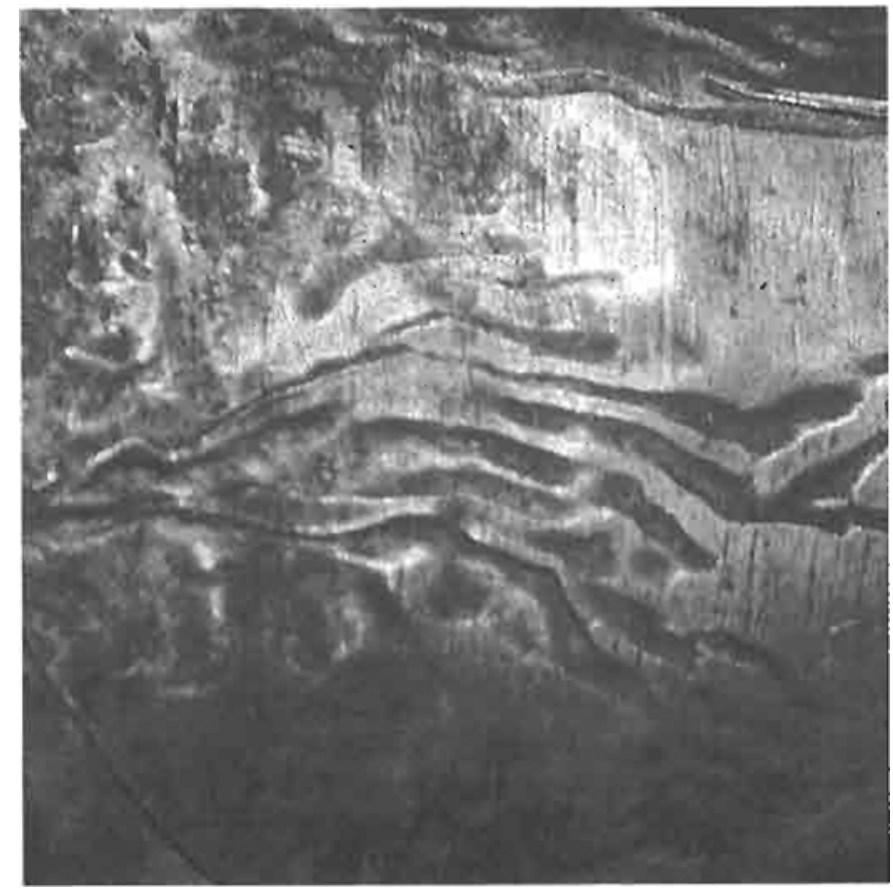

Fig. 4 Detail of creases on the gold foil covering the sceptre from Mapungubwe showing that the foil was not significantly shaped by repoussé working

the sheets. Pleats were held in place with rows of gold pins (Figure 5) and where two sheets of gold overlap the edges are not soldered, but are also held together with a row of pins.

The pins have also been made by smithing techniques and have tapering shanks (about $1 \mathrm{~mm}$ reducing to about $0.5 \mathrm{~mm}$ ) with an overall length of from 3.5 to $5 \mathrm{~mm}$. The shanks of some are rectangular in section, suggesting that they have been cut from sheet gold, but others have been roughly rounded by hammering. The heads of the pins have probably been formed by using a miniature nail-making iron (for example, a sheet of iron pierced with tapering holes which looks rather like a draw-plate).

Apart from the remains of what were obviously other animals, the gold foil objects include a bowl which was partly shaped by hammering, but was also creased and pleated, especially near the rim, and a sceptre, presumably indicating the status of the dead man. Examination of the sceptre shows that the holes for the pins were punched through from the outside, possibly by the pins themselves which fit the contours of the holes exactly, and the edges of the holes are now surrounded by a depression which originally accommodated the pin-heads. The edges of the gold sheets on the sceptre are very rough and were not cut with a blade or other tool. The knob on top of the sceptre is decorated with two rows of punched indentions.

The general impression of most of the sheet gold work from Mapungubwe is that considerable skill was exercised in making the pieces of foil, but that the knowledge of sinking and raising the sheet metal by the use of stakes was essentially lacking, as was knowledge of engraving and soldering.

One or two pieces of gold foil, however, are in a different class and have been worked into a true three dimensional shape, and then more extensively decorated. In particular there is the head of an animal which has been identified as a horse in the past, but which is, perhaps, more likely to be a crocodile (Figure 6). In particular, the eyes and ears have been shaped by smithing and then a row of teeth has been applied by rubbing a pointed tool on to the gold to make indentations. Besides this head, some legs exist among the Mapungubwe fragments which may be part of the same animal as they were also made by a more skilled smith than were most of the other fragments.

Finally, among the gold foil pieces are some semi-circular ones which have both scribed and punched designs. Only a simple, round punch, with a diameter of $0.3 \mathrm{~mm}$, was used, but it was applied to the back of the sheet to give rows of dots, and another tool was then used to scribe lines between the dots on the front of the foil (Figure 7).

Fig. 5 Back of a fragment of foil from Mapungubwe showing a row of pins in position 


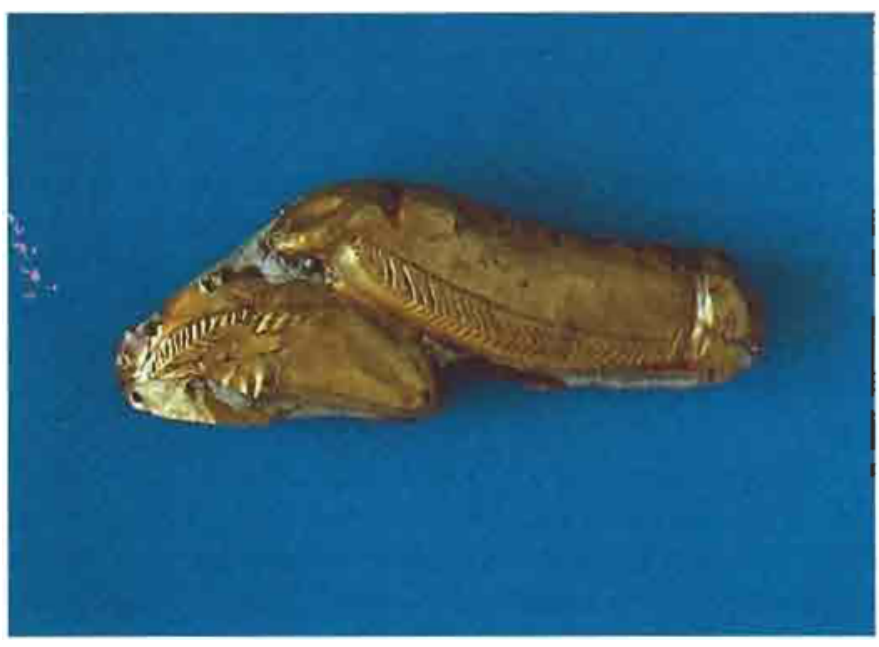

Fig. 6 Head of a crocodile (?) from Mapungubwe

Fig. 7 Back surface of a piece of gold foil from Mapungubwe which is decorated with punched and scribed lines. The punch was applied to the back, but the scriber to the front of the foil

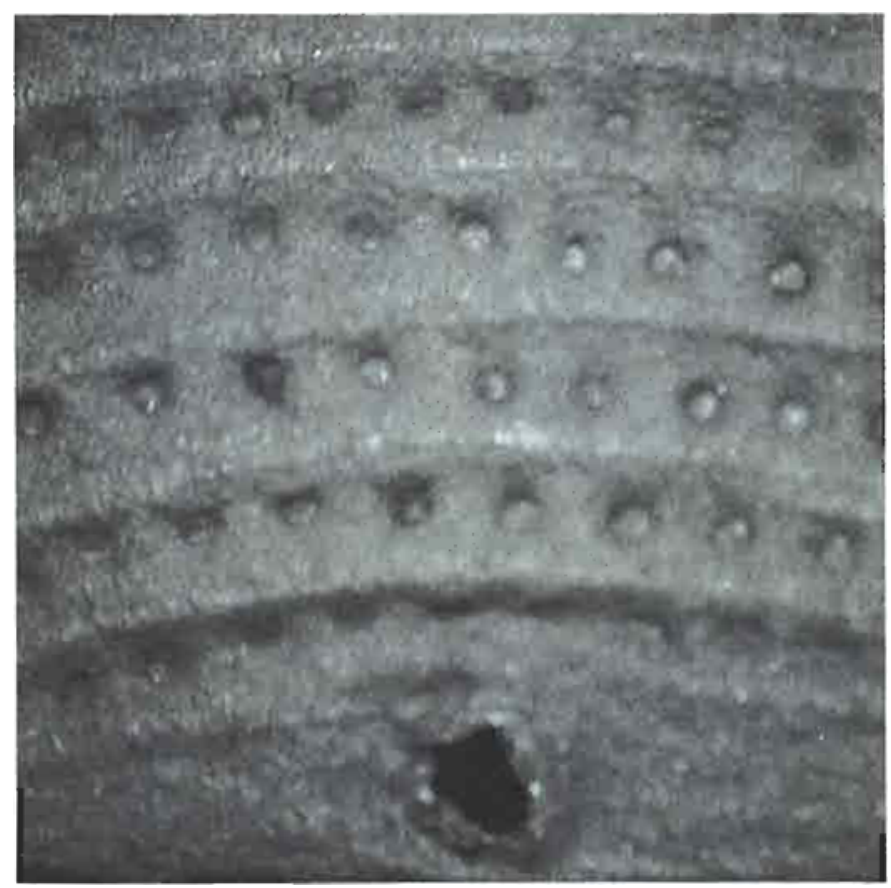

Beads

The gold beads from Mapungubwe (Figure 8) are of three types: the first is a flattened sphere (Figure 9) which was certainly made by casting and the second is similar, but has flat areas polished round the holes (Figure 9), presumably so that the beads fit more closely together when strung. These cast beads vary in size from as little as $1.5 \times 0.7 \mathrm{~mm}$ to $4.3 \times 2.0 \mathrm{~mm}$. The beads appear to have been cast individually, and the holes through their centres were 'cast-in', and

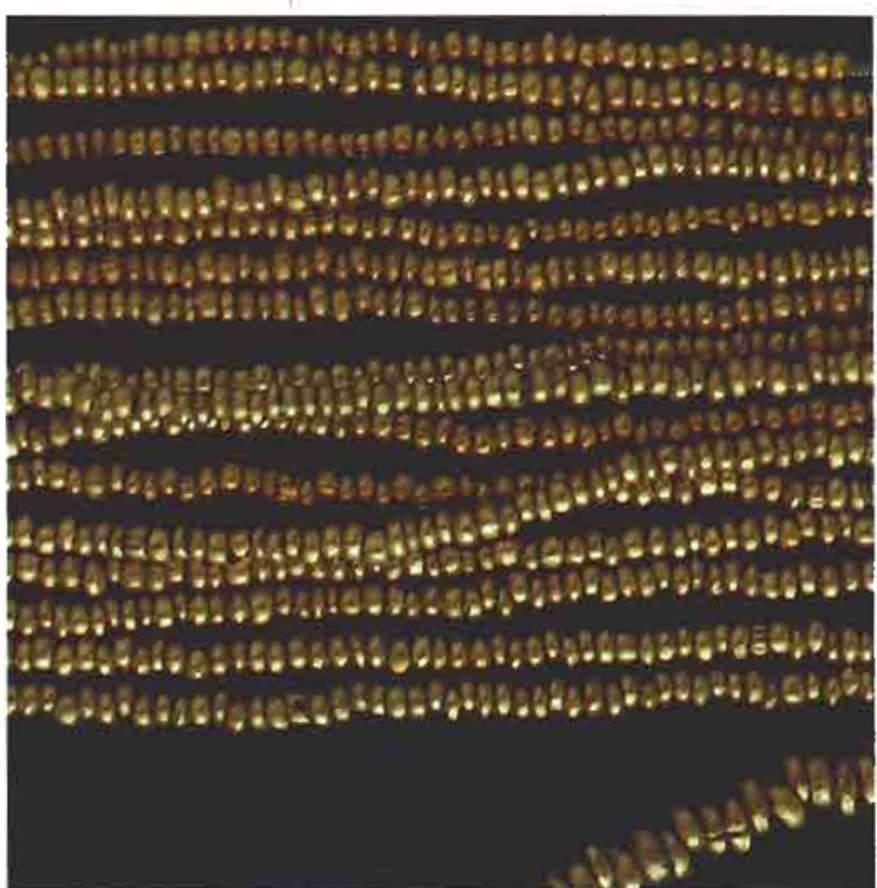

Fig. 8 Examples of the various types of beads found at Mapungubwe

Fig. 9 Beads from Mapungubwe, with the areas around some of the holes having been polished flat

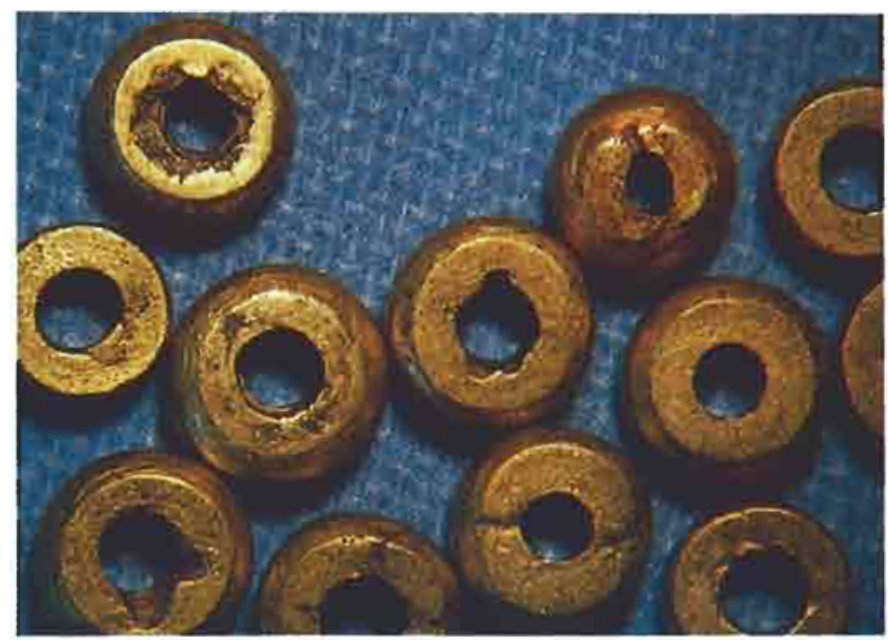

often show the presence of air bubbles when examined microscopically. Some of the beads are decorated by having grooves in the surfaces (Figure 10), but it was impossible to tell whether they were cast-in or cut after casting. From the state of wear of the beads, the latter is perhaps more probable. It has been suggested that the cast beads were made by the lost-wax process (7), but they are of such a simple shape and show no evidence of the removal of a sprue (except possibly for those with polished surfaces) that individual 


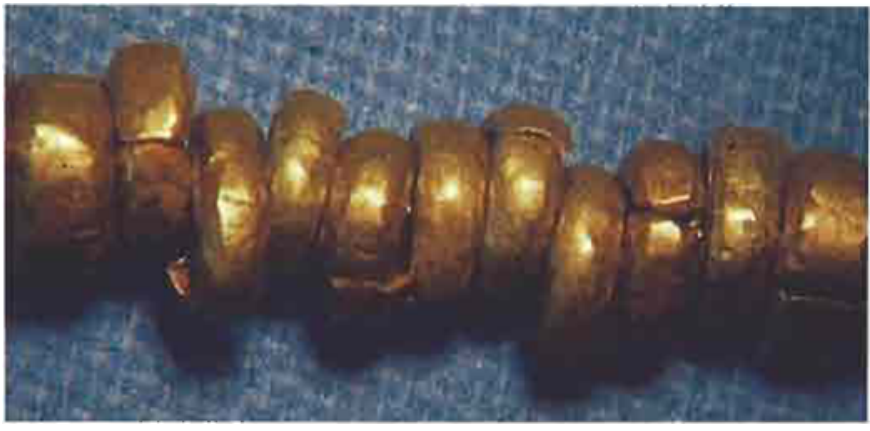

Fig. 10 Beads from Mapungubwe possessing decorated surfaces

casting cannot be excluded. With such small beads the use of moulds would be unnecessary, as the molten metal would tend to form small, flattened spheres quite naturally. The only problem with the individual casting hypothesis is how the holes were cast exactly in the centre of the bead, and it is clear that carrying out practical experiments would be necessary to clarify this uncertainty.

The third type of bead from Mapungubwe is made from small pieces of gold 'wire', with a roughly square or rectangular crosssection, which have been bent round into a loop with butted ends (Figure 11). They have a similar size variation as the cast beads described above, from $2.1 \times 1.2 \mathrm{~mm}$ to $3.9 \times 1.6 \mathrm{~mm}$. The surface of the gold shows typical hammering facets when examined microscopically, and the original 'wire' was clearly made by smithing techniques.

\section{Wire}

Gold wire, and jewellery made from it, forms the third class of gold objects found at Mapungubwe, and is the most important from a technological point of view. The manufacture of gold wire in prehistoric Europe has been extensively studied in recent years, and the origins of wire drawing have been argued as a post-Roman invention, at least in Britain if not in the rest of Europe (8). In Africa, wire-drawing in several cultures has been studied by ethnographers (9-12), and wire-drawing dies have been found in the archaeological

Fig. 11 Beads from Mapungubwe made from strips of gold 'wire'

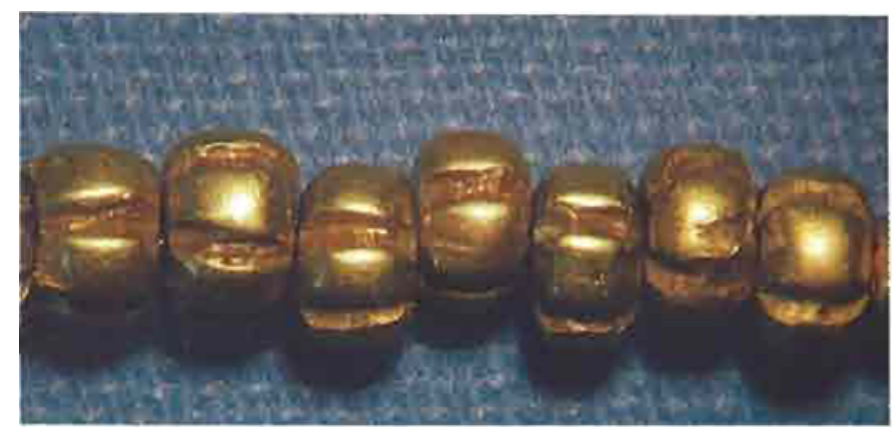

excavations at Ingombe Ilede (13). However nothing is known about the introduction of the technique in this region, or whether it was an independent invention which predates European penetration into the interior.

At Mapungubwe, the 'wire' is of two types, some of it being approximately round in cross-section and some consisting of a strip of metal with a trapezoid cross-section which has been cut from the edge of a sheet of gold. The latter is not 'wire' in the modern sense of the term, but was used to make bangles by tightly twisting it into a helix (Figure 12) around a bundle of fibres so that it forms a hollow tube.

Microscopic examination of numerous fragments has shown that the original gold sheet was of the order of 0.2 to $0.3 \mathrm{~mm}$ thick and that it has beencut using a sharp blade and a straight edge (Figure 13). The strips vary in width between 1 and $1.5 \mathrm{~mm}$. In places where

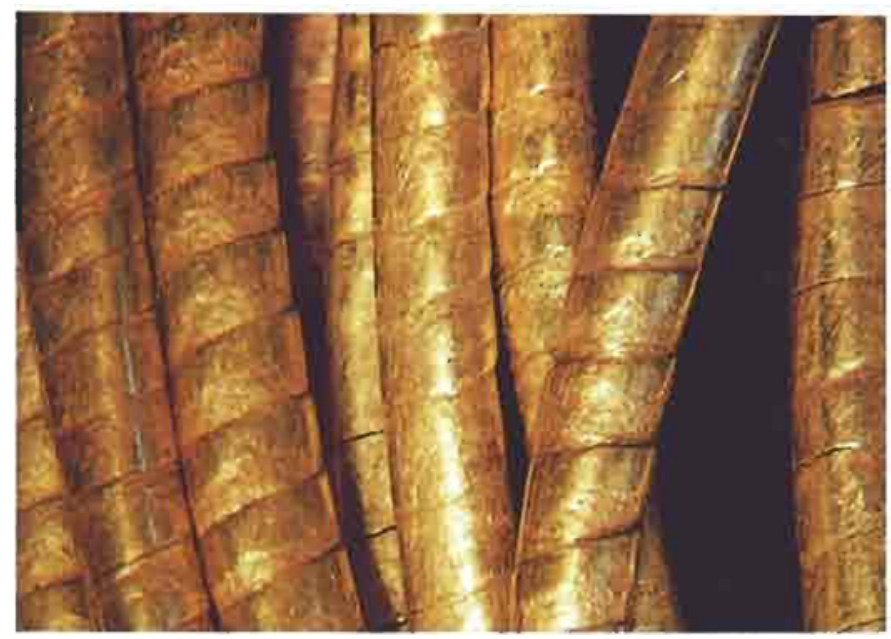

Fig. 12 Bangles from Mapungubwe made by winding a strip of gold tightly into a helix

Fig. 13 Gold strip from a damaged bangle showing the tool marks from cutting

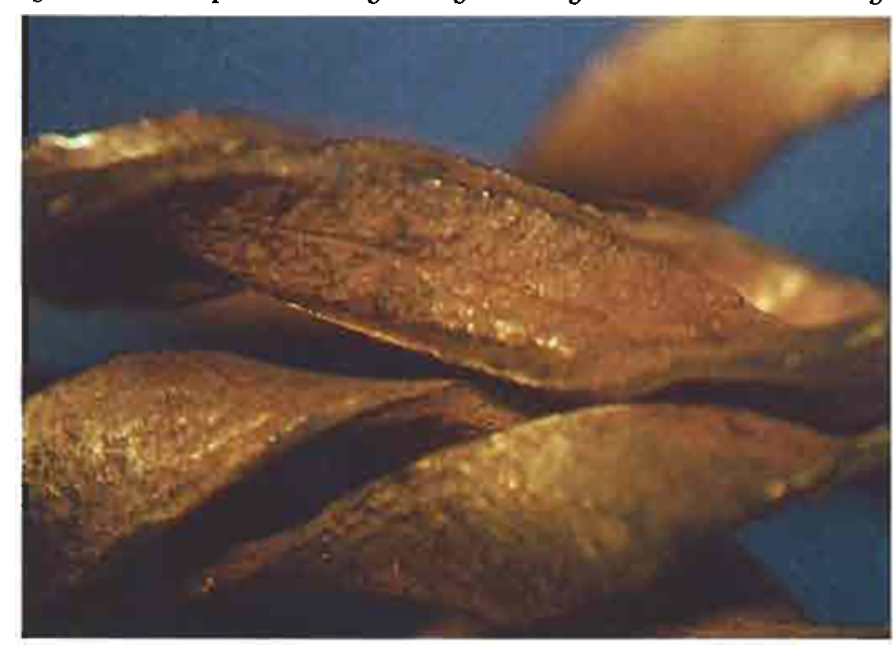


two strips join, they are coiled together for several turns, and again no solder is present. The inner surface of the coils is rougher than the outside and, again, which probably indicates that the gold sheet was hammered out on a stone anvil.

The true wire, like the gold strip, was used to make bangles by coiling into helices (Figure 14), and joins were also made by interlocking the free ends for several turns. The diameter of wire of individual bangles is very even within the range 0.5 to $0.7 \mathrm{~mm}$. The outer surfaces of the bangles are worn rather flat, but this wear is present all over the spiral, both inside next to the wearer, and outside, and appears to be too even to be the result of wear in use. The surface of the wire within the spiral is rough and has longitudinal parallel striations which are unlike those found on European prehistoric wire. The wire does not have the typical appearance of having been drawn, but nor do the features which can be seen under the microscope correspond exactly with the well known methods of making round wire by hand. It seems likely that, at this early period, the wire was made by hammering, combined with some sort of abrasive smoothing technique, perhaps using sand or a groove in the edge of a stone.

\section{Gold at Great Zimbabwe}

The ruins at Great Zimbabwe have been the subject of much speculation regarding their origins and although several excavations have been carried out, most of the gold finds are unstratified and, therefore, undatable. Nevertheless they clearly belong to the same tradition as that identified at Mapungubwe, but with the added dimension that there is clear evidence for the working of gold, since among the finds is a fragment of a crucible with globules of gold trapped in the surface and also numerous other small globules of gold which are clearly the products of melting operations.

Unfortunately no gold foil sculptures have survived, but there is evidence in the form of scraps of gold foil (Figure 15) and small gold pins to suggest that they existed. Some of these fragments of foil have holes in them.

The Great Zimbabwe ruins have not produced large numbers of gold beads, but the chance finds have shown that the main type is a small cast flattened sphere, without polished sides. These beads correspond exactly to the ones found in such large numbers at Mapungubwe.

Finally, from Great Zimbabwe, there are the fragments of gold wire, and here there is definite evidence for wire-drawing. In fact both hammered and drawn wire is present, as well as pieces of gold strip wound into a spiral.

What is especially interesting about the Great Zimbabwe finds is that a mass of copper alloy jewellery exists for the later periods on the site, and a brief examination of this has shown that the same techniques of jewellery-making continued after the disappearance of gold. However, developments in technique can also be expected, and this later jewellery represents a rich potential source of information for the historians of technology in the future.

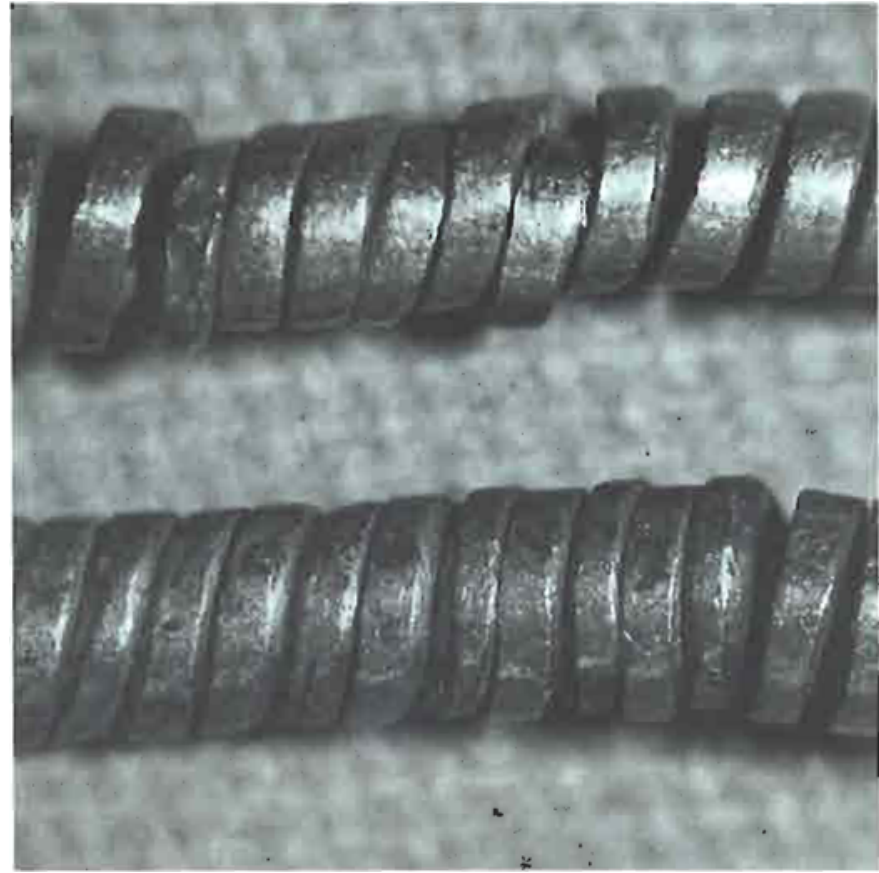

Fig. 14 Gold wire from Mapungubwe wound into a helix for use as a bangle

Fig. 15 Scraps of gold foil from Great Zimbabwe with holes made by small nails

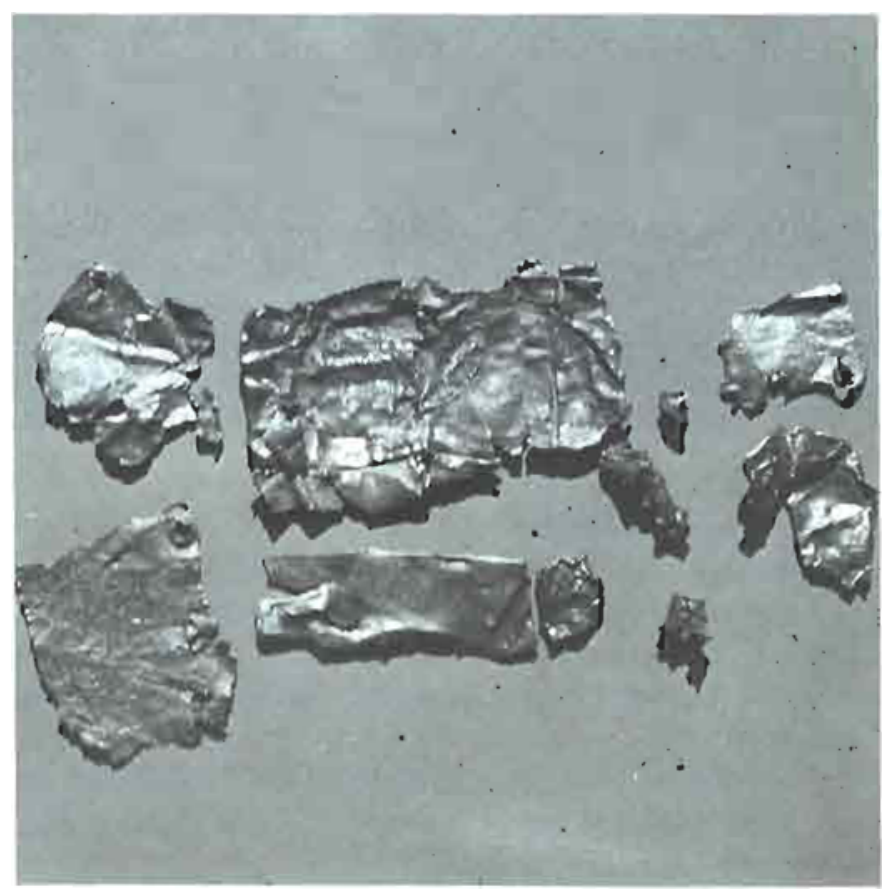




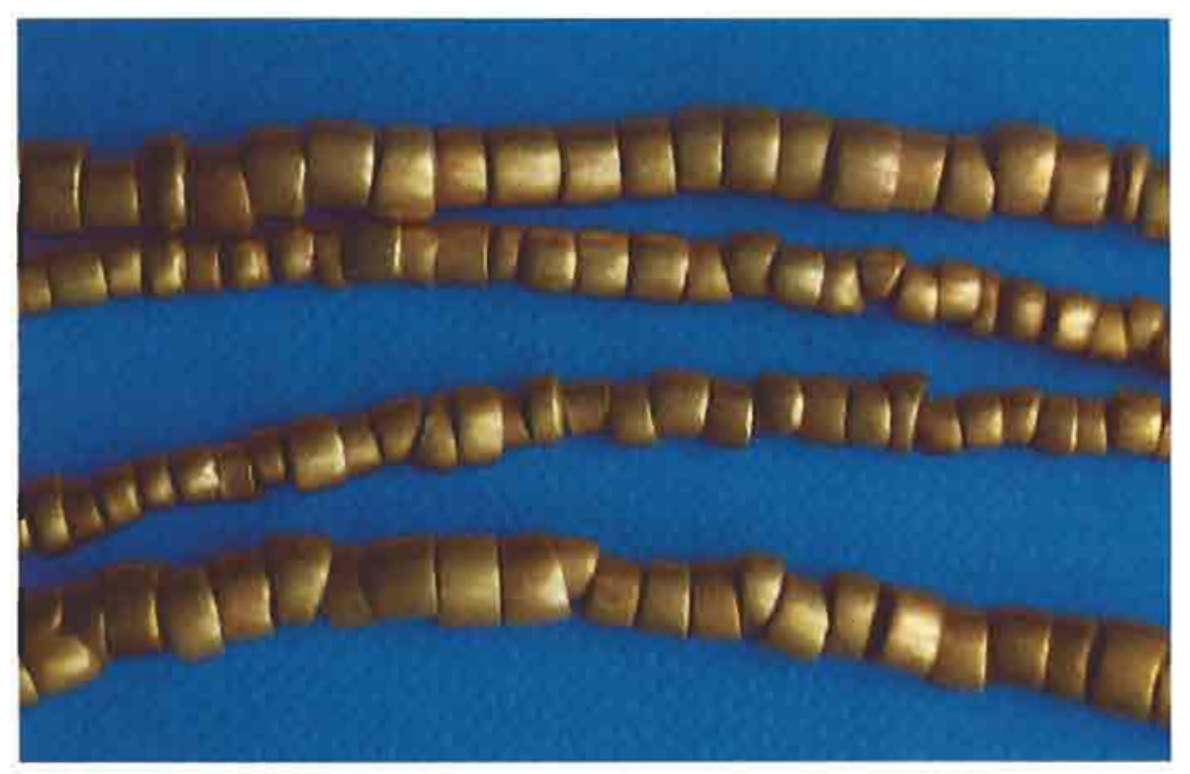

Fig. 16 Gold beads from Ingombe llede. Some show signs of extensive wear

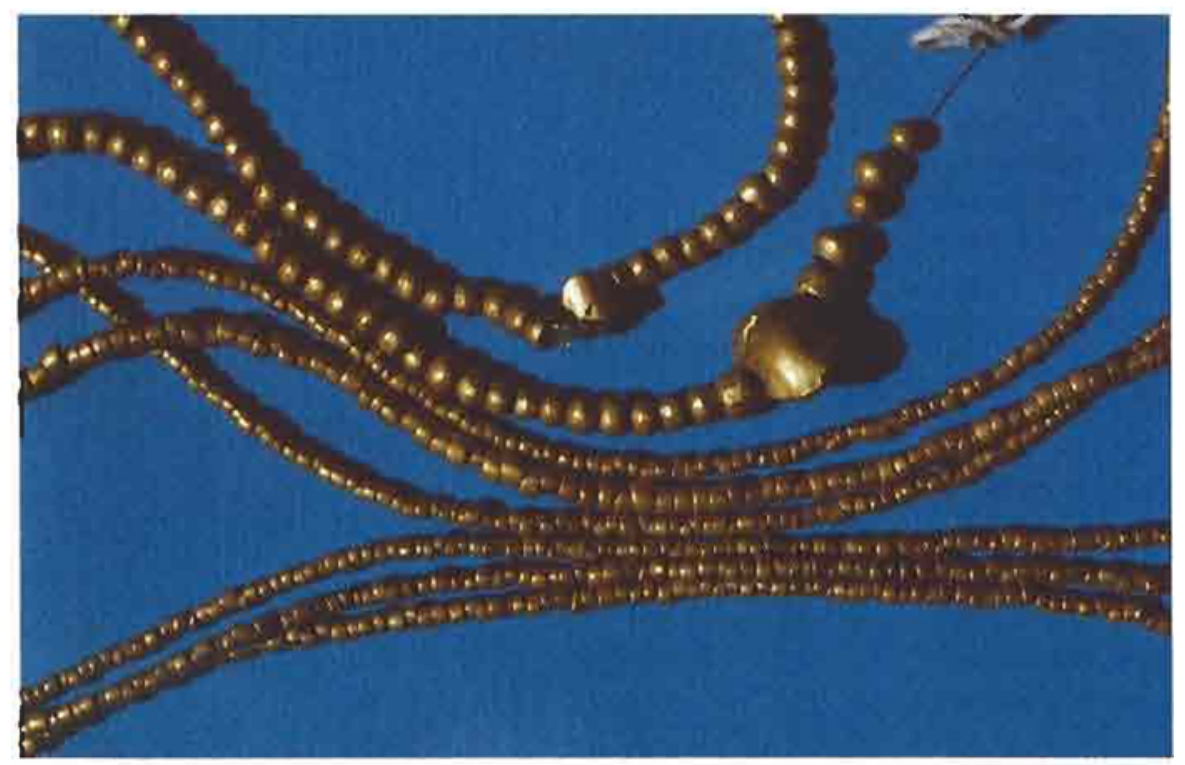

Fig. 17 Gold beads from Ingombe llede including two large ones shaped like rounded cubes

\section{Gold at Ingombe Ilede}

Of the three major sites which have produced gold finds, only those from Ingombe Ilede have been excavated under modern conditions so that the complete contents of the individual graves are known. The great importance of the sites lies not only in the presence of gold jewellery in the graves, but in the fact that metalworking tools and other implements were buried with the dead. These included several hammers and wire-drawing dies, blacksmiths' tongs, hoes and chisels.
At Ingombe Ilede only one fragment of gold foil was recorded, and this was attached to an imported sea shell. However, cast gold beads were found in great profusion, many of them showing signs of extensive wear in that they had lost their symmetrical shape by rubbing on adjacent beads (Figure 16). A few of the beads were of the 'strip' type, bent into a loop with butted ends. On the whole, the beads had a similar size range to those from Mapungubwe, except that at Ingombe Ilede there are several large beads, some of which are shaped like cubes with rounded-off corners (Figure 17), 

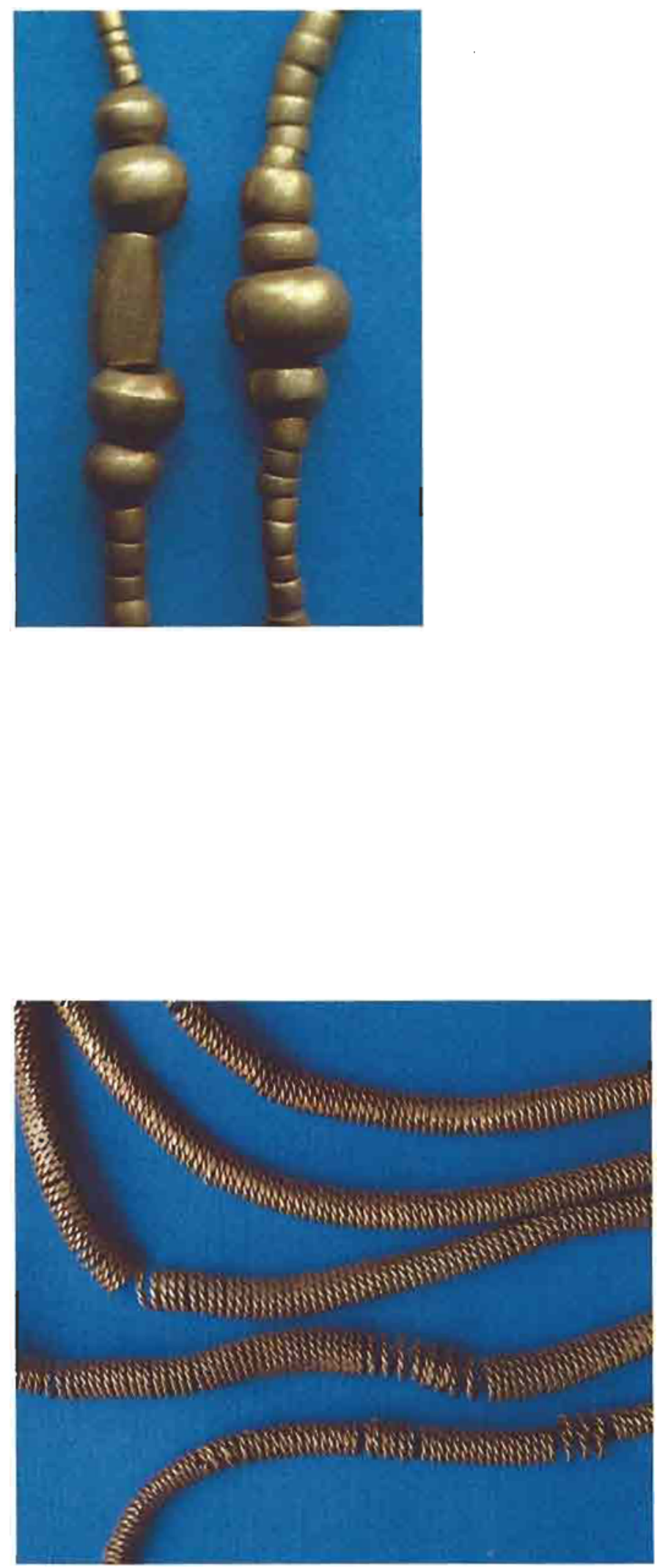

Fig. 18 (top left) Detail of a necklace from Ingombe Ilede showing larger beads in the centre; one of these is a gold cylinder

Fig. 19 (bottom left) Fragments of spirally wound wire armtets from Ingombe llede

Fig. 20 (top right) Wire armlets from a cave in the Belingwe Hills, south-east of Bulawayo. 
Fig. 21 Fragments of gold manufacturing debris from Dhlo Dhlo

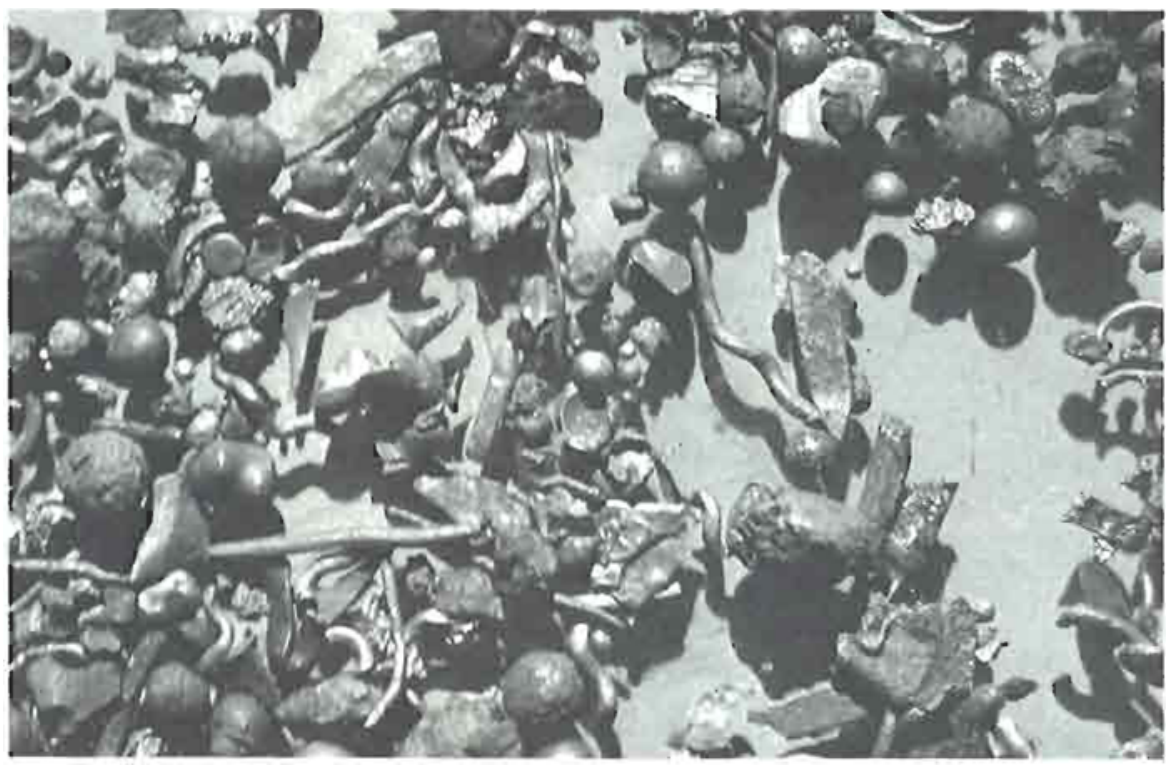

\section{Gold at Other Sites}

Apart from the three sites discussed above, gold has been found in an Iron Age context at a number of excavations in Zimbabwe and the Northern Transvaal. In most cases these have consisted of one or two gold beads or globules resulting from casting. However, Dhlo Dhlo in Zimbabwe, where the main period of occupation seems to have been the 17th and 18th centuries, has produced a large number of minute fragments of debased gold which obviously represent manufacturing debris (Figure 21). They include nuggets, cast spheres, pins, beads, gold foil and gold wire, some hammered and some drawn. Many of these are clearly made of very base gold, but what is important is that some of the fragments have traces of a black glassy material still adhering to them, showing that they are unfinished.

\section{Conclusions}

The period covered by the gold finds in Southern Africa coincides with the establishment and development of trade between the interior and the East Coast. It has, therefore, been natural to ask whether the actual objects of gold were themselves traded back along this route from the coast to the interior. This examination has shown that the manufacturing technique of the gold is relatively unsophisticated and there is no evidence to suggest that it is not of indigenous workmanship. In fact, the techniques used are so simple, even crude when considering the shaping of the gold foil, that it would be difficult to believe that the sheet gold objects were not from the interior even if they had been discovered on the coast. The absence of soldering and of the skill at repoussé work, which were well developed in the outside world, is a sure indication that the gold of Mapungubwe and the related sites was produced by Africans, who had had no exposure to such techniques, during the later Iron Age. Unfortunately the site of manufacture of the Mapungubwe and Ingombe Ilede gold remains unknown, but some gold melting was certainly carried out at Great Zimbabwe and at Dhlo Dhlo. No doubt future excavations will resolve this uncertainty.

\section{Acknowledgements}

The author's three-week visit to Africa to study the Iron Age gold was made possible through the generosity of the International Gold Corporation, and he is especially grateful to Drs. G. Gafner and W.S. Rapson for their efforts on his behalf The actual trip was kindly organised by Mrs. Elizabeth Voigt of the Transvaal Museum and the author received further assistance from Andrie Meyer and Helgaard Prinsloo at Pretoria University. But, above all, thanks are due to the curators of the fou collections which were studied; Professor J.F. Eloff at Pretoria University, Mr. N.M Katanekwa and Mr. M. Mukela at the Livingstone Museum in Zambia, Miss Carolyn Thorp at the Queen Victoria Museum, Harare, and Mr. M. McLeod and Dr. B.J. Mack at the British Museum, London.

\section{References}

Several general accounts have been published in recent years of the African Iron Age, but the one used in the preparation of this paper was D.W. Phillipson, "The Later Prehistory of Eastern and Southern Africa', London, 1977.

1 L. Fouché, 'Mapungubwe I', Cambridge, 1937

2 G.A. Gardner, 'Mapungubwe II', Pretoria, 1963

3 P.S. Garlake, 'Great Zimbabwe', London, 1973

4 R. Summers, K. R. Robinson and A. Whitty, 'Zimbabwe Excavations', Occasional Papers of the National Museum of Southern Rhodesia III, 23a, 196

S B.M. Fagan et al., 'Iron Age Cultures in Zimbabwe', Vol. II, London, 1969

6 B.M. Fagan, 'Ingombe Ilede: Early Trade in South Central Africa', McCaleb Module in Anthropology, No. 19, 1972

7 E. Frey, 'Methods of Goldworking at Ingombe Ilede', in B.M. Fagan, 'Iron Age Cultures in Zambia', Vol. I, London, 1967, pp. 237-238

8 W.A. Oddy, 'Gold Wire on the Thetford Jewellery and the Technology of Wire Production in Roman 'Times', in C. Johns and T. Potter, 'The Thetford Treasure', British Museum, London, 1983, pp. 62-64

9 H.A. Stayt, 'The Bavenda', International Institute of African Languages and Cultures, Oxford, 1931, pp. 64-68

10 K.G. Lindblom, 'Wire-Drawing, Fspecially in Africa', Statens Etnografiska Museum, Smärre Meddelanden No. 15, Stockholm, 1939

11 J.A. van Schalkwyk, 'Dic Vervaardiging van Koperdraad en Krale deur die Ndzundza', Ethnology (South A frican Journal of Ethnology), 1982, 5, (2), 15-20

12 W. Cline, 'Mining and Metallurgy in Negro Africa', General Series in Anthropology No. 5, Menasha, 1939, pp. 109-111

13 See (5), Fig. 35 